\title{
INOVAÇÃO E REGULAÇÃO NO TRANSPORTE PÚBLICO
}

\section{INNOVATION AND REGULATION IN PUBLIC TRANSPORT}

\author{
Rafael Mendes Lübeck ${ }^{1}$; Milton Luiz Wittmann ${ }^{2}$; Angélica Skrebsky Richter ${ }^{3}$; Marcia Santos da Silva ${ }^{4}$ \\ ${ }^{1}$ Universidade Federal de Santa Maria - UFSM - Santa Maria - Brasil \\ rafael.lubeck@gmail.com \\ ${ }^{2}$ Universidade Federal de Santa Maria - UFSM - Santa Maria - Brasil \\ wittmann@profwittmann.com \\ ${ }^{3}$ Universidade Federal de Santa Maria - UFSM - Santa Maria - Brasil \\ angelica.keca@gmail.com \\ ${ }^{4}$ Universidade Federal de Santa Maria - UFSM - Santa Maria - Brasil \\ mssrs@terra.com.br
}

\section{Resumo}

O presente artigo foi desenvolvido com o objetivo de verificar se os órgãos reguladores de atividades de transporte público podem induzir processos de inovação. Para tanto, foi analisada a criação, o desenvolvimento e a implantação do sistema de bilhetagem eletrônica em três cidades e uma região metropolitana do Estado do Rio Grande do Sul. A pesquisa de campo compreendeu entrevistas com gestores das empresas de transporte, associações de transportadores e representantes do Poder Concedente e análise documental para levantamento histórico do setor e da legislação específica para a bilhetagem eletrônica. A pesquisa de campo resultou em dados de natureza qualitativa que foram analisados com a aplicação da análise de conteúdo. As considerações finais apontam que o sistema de bilhetagem possui características inovadoras pelas melhorias e novas combinações proporcionadas pelo mesmo, além do Poder Concedente constituir-se como agente indutor de inovação proporcionando ganhos para todos os envolvidos no transporte público (usuários, empresas e Poder Concedente).

Palavras-chave: inovação; regulação; bilhetagem eletrônica.

\section{Introdução}

O conceito de inovação ganhou ênfase e se difundiu com os trabalhos clássicos de Schumpeter no século XX que nortearam o debate sobre as teorias do Desenvolvimento Econômico sob o arcabouço teórico da inovação e desenvolvimento. Tal destaque se deve aos efeitos das inovações de gestão, processo e produto com vistas ao desenvolvimento das nações, instituições e empresas (SMITH, 2008; BYKFALVY, 2007; CHESBROUGH, KARDON, 2006; FRANCIS, BESSANT, 
2005). Na visão schumpeteriana, a tecnologia influencia o desenvolvimento com impactos na dimensão econômica e social que se reflete na produtividade e crescimento da riqueza (SCHUMPETER, 1982; NELSON, WINTER, 2005; KEUPP, GASSMAN, 2009).

As ações dos governos influenciam o desenvolvimento por meio de estratégias de investimentos, regulação e políticas de incentivos que estimulam inovações no ambiente social e empresarial. Segundo Allen et al (1978) essas estratégias podem até mesmo promover a elevação dos níveis de inovação pelo incremento da competitividade ou o aumento de exigências que estimulem empresas a inovar para atingir níveis de qualidade desejáveis ou determinados pelos órgãos reguladores. Contudo, segundo Passos (1999) faz-se necessária a inter-relação positiva entre o público e o privado de forma a alavancar a obtenção de meios tecnológicos, processos ou mesmo condições ambientais e logísticas para a criação e manutenção da inovação.

Ressalta-se que a regulação, por si só, pode não resultar em incremento de inovações a partir do momento em que inibir o desenvolvimento das empresas ou mesmo não proporcionar condições para este desenvolvimento. Segundo Schumpeter (1982; 1942), as inovações, a partir de medidas de políticas regulatórias, atingem parâmetros de racionalidade em contraponto à criatividade, outrossim, políticas de incentivo e medidas de regulação são aceitáveis dentro do ambiente competitivo se utilizadas como formas de criar o progresso técnico, se o ambiente de competição de preços e mercados estiver gerando resultados negativos ou indesejáveis com perdas de lucratividade ou falência para as empresas e desemprego para os trabalhadores. Nos casos estudados, experiências que ocorreram na década de 1980 em que havia concorrência, resultaram em ineficiência e ineficácia aos sistemas de transporte público estudados. Portanto a criação de monopólios regulados está em consonância com as falhas de mercado mencionadas por Schumpeter.

O papel desempenhado pelo Estado, no que se refere a atividades regulatórias, poderia se concentrar em três dimensões segundo Burlamaqui, (2005): a) estimular à cooperação tecnológica, alavancando os investimentos empresariais de longo prazo; b) administrar a destruição criadora, monitorando e controlando a ocorrência de práticas predatórias; e c) criar instituições que possibilitem a implementação das medidas anteriormente citadas (itens a e b).

Entre os estudos sobre inovação, ganharam destaque os que se referem ao setor de serviços. $\mathrm{O}$ setor de serviços é de extrema diversidade e inovação distinguindo-se na sua organização e execução em relação a formas tradicionais (HIPP, 2008; DJELLAL, GALLOUJ, 2007). Gallouj e Sanson (2007) argumentam que as diferenças em termos de inovação são mais significativas no cerne dos serviços do que entre determinados setores industriais. Pesquisas de inovação são relativamente recentes e a pesquisa de inovação na área de serviços é ainda mais recente (HAMDANI, 2007; JACOBY, 
RODRIGUEZ, 2007), pois somente na sociedade pós-industrial as inovações em serviços começaram a ter destaque (SIMMIE, STRAMBACH, 2007; CAMACHO, RODRIGUEZ, 2005).

A importância da pesquisa se reflete na necessidade de pesquisar os impactos das inovações em setores regulados para o avanço do conhecimento sobre o papel das atividades regulatórias na economia. Este fator é especialmente relevante, pois está inserido nas dinâmicas sociais e econômicas contribuindo para o debate científico e empresarial visando o desenvolvimento social e econômico. O presente trabalho integra um projeto de pesquisa sobre inovação no transporte público em cidades do Rio Grande do Sul, financiado com recursos do CNPq (Conselho Nacional de Desenvolvimento Científico e Tecnológico) e FAPERGS (Fundação de Amparo à Pesquisa do Estado do Rio Grande do Sul). O artigo foi desenvolvido com o objetivo de verificar se órgãos reguladores de atividades de transporte público podem induzir processos de inovação. Para tanto, foi analisado a criação, desenvolvimento e implantação do sistema de bilhetagem eletrônica em três cidades e uma região metropolitana do Rio Grande do Sul.

Inicialmente foi construído um referencial teórico que norteou a construção do conceito de inovação adotado para este trabalho e aspectos que deveriam ser observados nas investigações em campo. A pesquisa de campo coletou depoimentos de gestores das empresas e associações do transporte coletivo urbano e representantes do Poder Concedente. Realizou-se também análise documental para levantamento histórico do setor e da legislação específica para a bilhetagem eletrônica que foram posteriormente analisados com a utilização de Análise de Conteúdo a posteriori. As considerações finais apontam que o sistema de bilhetagem possui características inovadoras pelas melhorias e novas combinações proporcionadas pelo mesmo, além do Poder Concedente constituir-se agente indutor de inovação.

\section{Aspectos de inovação e regulação}

No que tange a inovação e seu desenvolvimento, Schumpeter (1942) declara que o impulso fundamental que põe e mantém em funcionamento a máquina capitalista procede de novos bens de consumo, dos novos métodos de produção ou transporte, dos novos mercados e das novas formas de organização industrial criados pela empresa capitalista. Resumindo, atividades inovadoras são as geradoras primárias da mudança econômica, por isso as economias mundiais concentram-se em produtos e serviços que agreguem valor pela inovação como fonte de criação e recriação de mercados (SIMMIE, STRAMBACH, 2007). Nota-se que o desempenho da inovação está ligado intrinsecamente com o desenvolvimento das atividades econômicas de um país (DASCHS, EBERRSBERGER, LÖÖF, 
2008; SIMMIE, STRAMBACH, 2007), pois as inovações transformam e criam mercados estimulando o crescimento econômico (SMITH, 2008, MAVEL, LUMPKIN, 2007).

No setor de transporte público a introdução de novas tecnologias tornou-se fator de recriação da própria atividade, desenvolvendo e qualificando os serviços oferecidos. A inovação nos serviços é frequentemente assimilada à adoção de sistemas tecnológicos (particularmente, sistemas informatizados) advindos da inventividade dos setores industriais, em detrimento de outras fontes de inovação menos tangíveis (GALLOUJ, SANSON, 2007). Na interpretação de Gallaugher (2007), o recurso tecnologia leva à eficácia operacional fazendo com que as empresas melhorem a qualidade de seus produtos e serviços.

A inovação pode ser vista como um processo que ocorre em diversas fases partindo de algum problema específico identificado que passa, necessariamente, pela sistematização das dificuldades existentes, a percepção de uma prática inovadora e os processos políticos que envolvem a aceitação da inovação por parte dos diversos agentes envolvidos no processo (LOUNSBURY, CRUMLEY, 2007). A existência e permanência das empresas no mercado são possíveis a partir do momento em que estas passam a inovar, criando e recriando suas estruturas com o objetivo de buscar novas soluções para os mercados emergentes. A inovação passa a ser um processo contínuo em um movimento de destruição criadora no qual a empresa assimila conhecimento e gera novas ideias, produzindo novas combinações que revolucionam a estrutura econômica, destruindo a antiga e promovendo o desenvolvimento econômico (SCHUMPETER, 1942; SCHUMPETER, 1982).

O caráter estacionário da empresa criticado por Joseph Schumpeter é o mesmo questionado por outras correntes do pensamento econômico. Novas interpretações do comportamento da empresa emergem trazendo a empresa organizada: a empresa instituição, que é analisada dentro da dimensão social e política do contexto de sua atuação; e as contribuições de Ronald Coase (1938) e Oliver Willianson (1979) com a Teoria dos Custos de Transação, que traz novas questões sobre o arranjo institucional alternativo ao mercado para a efetivação das transações econômicas. Estes constructos são críticas ao caráter estacionário da empresa que estão fundamentadas na facilidade de elaboração modelos de equilíbrio e crescimento econômico.

A teoria da empresa começa a elaborar modelos de mercado que absorvem a natureza da empresa em cenários de oligopólios, surgindo a necessidade de analisar as questões ligadas à dinâmica tecnológica e às atividades de pesquisa e desenvolvimento. Schumpeter (1942) já tinha mencionado a natureza da empresa como chave para a construção teórica do capitalismo, tentando explicar as empresas do século XX. Segundo o autor, a inovação é a força motriz do crescimento econômico em longo prazo, que destruiria as empresas atuais (processo de destruição criadora). 
Os processos de inovação criam e recriam mercados e processos. No setor de transporte público, a introdução de novas tecnologias associadas à natureza da atividade tornou-se fator de recriação da própria atividade, desenvolvendo novas oportunidades de mercado e qualificando os serviços oferecidos. Como resposta ao acirramento da competitividade e das exigências do mercado globalizado, muitas empresas se viram pressionadas a inovar, ou seja, criar novos produtos e serviços dentro da empresa utilizando conexões entre novos e antigos cenários, adaptando suas estruturas e processos a novas demandas e modelos de gestão (FRANCIS, BESSANT, 2005).

A complexidade da criação de inovação envolve o uso dos recursos da organização para criar as condições necessárias ao processo. As diferenças de condições entre cada organização causam uma variação quanto à intensidade desse processo, demandando maiores ou menores esforços. A intensidade de uma inovação depende da competência da empresa, ou seja, o que pode ser sentido como uma grande mudança para uma organização pode ser uma simples adaptação para outra. As empresas podem antecipar e explorar as novas opções abertas pela iminente onda da inovação, adaptando suas capacidades, formando novas alianças, preparando sua organização, seu processo de gerenciamento ou sua cultura (DURAND, 1997). As mudanças no ambiente e as diferentes percepções geradas pelos gestores de uma organização promovem o aumento da confiança, da cooperação e do comprometimento, contribuindo para o aprendizado e o desempenho da organização (FLOYD, LANE, 2000).

\subsection{O que se entende por inovação?}

A inovação, a partir dos conceitos lançados por Schumpeter (1982, 1942), é compreendida como: a introdução de um novo bem: um bem com que os consumidores ainda não estejam familiarizados ou de uma nova qualidade de um bem; introdução de um novo método de produção: um método que ainda não tenha sido testado pela experiência no ramo próprio da indústria de transformação, que, de modo algum, precisa ser baseado numa descoberta cientificamente nova, e pode consistir também em nova maneira de manejar comercialmente uma mercadoria; abertura de um novo mercado: um mercado em que o ramo particular da indústria de transformação do país em questão não tenha ainda entrado, quer esse mercado tenha existido antes ou não; conquista de uma nova fonte de matérias-primas ou de bens semimanufaturados: bens produzidos independentemente do fato de que essa fonte já existia ou teve que ser criada; estabelecimento de uma nova organização: organização de qualquer indústria, como a criação de uma posição de monopólio (por exemplo, pela trustificação) ou a fragmentação de uma posição de monopólio. 
O estudo da inovação é complexo porque a inovação per se não existe. A inovação é efêmera, difícil de capturar, por isto no seu estudo tenta-se defini-la para compreendê-la. Só sabe-se que algo é inovador pós-facto, ou seja, após o sucesso da inovação. A inovação é naturalmente muito difícil de medir, sendo que há duas razões para esta afirmação. Primeiro pelo fato de que a maioria das teorias referentes a este tema remete à categoria de serviços como algo intangível e interativo. Esta literatura sugere que os serviços estejam orientados frequentemente às mudanças contínuas (TETHER, 2005). Segundo, pelo fato de a inovação nos serviços ser associada diretamente à inovação em processos, desconstruída uma imagem semelhante à inovação de produtos. As definições de inovação incluem o desenvolvimento e a execução de "algo" (JONG, VERMEULEN, 2003).

A inovação representa a renovação de processos dentro das organizações (BESSANT et al, 2005) e pode ser entendida como uma ideia, uma prática, um comportamento ou um produto manufaturado que seja percebido como novo pela unidade que vai adotá-la (TARAFDAR, GORDON, 2007). Segundo Markard e Trufer (2008), a inovação tem sido definida de diferentes níveis para diferentes propósitos de pesquisa. Dentro desses diferentes níveis surge a análise das inovações e das transformações fundamentais de setores econômicos, que é um dos campos clássicos de pesquisa na literatura administrativa.

A inovação neste trabalho tem como orientação conceitual à compilação do pensamento de Smith, (2008), Tether (2005), Jong e Vermeulen, (2003), Tarafdar e Gordon, (2007), Sundbo e Gallouj (1998), Davenport, (1992), Barras (1986) e Schumpeter, (1982, 1942) que argumentam que a inovação é procedente de novos métodos ou procedimentos que produzem um efeito benéfico, ou seja, ela não existe por si (a inovação per si não existe), já que essa somente existe quando associa-se a algo. Desta orientação conceitual deduziu-se que: inovação é o efeito causado por algum novo meio tecnológico, novo pensamento, novo conhecimento, nova ideia, nova forma de proceder aplicados em algo novo ou pré-existente que causa transformações benéficas para produtos, serviços, pessoas, organizações ou sociedade e que tenha resultados multifacetados e perceptíveis como inovadores.

\subsection{Forças que influenciam a inovação em serviços}

As inovações em serviços são influenciadas por um conjunto de forças que atuam internamente e externamente no processo de inovação e foram representadas por Sundbo e Gallouj (1998) em um modelo que as identifica (driving forces) como incentivos ou obstáculos no processo. As forças que atuam externamente são compostas pelas forças chamadas Trajetórias, que estão divididas em 
profissional, gerencial, tecnológica, institucional e social e são compostas pelos agentes representados pelos clientes, competidores, governo e fornecedores.

As forças internas que atuam no processo de inovação são definidas como administração e estratégia, setor de inovação e recursos humanos e são representadas pelos colaboradores da empresa envolvida no processo de inovação. Entretanto, a composição destas forças pode assumir diferentes composições em cada organização. No modelo proposto por Sundbo e Gallouj (1998) as forças Trajetórias são representadas pelas ideias e lógicas difundidas no sistema social e que atuam externamente. Estas forças estão divididas em: trajetórias profissionais: representadas pelos métodos, conhecimentos e regras de comportamento características dos diferentes serviços profissionais; trajetórias gerenciais: compostas pelas ideias de novos desenhos organizacionais, como os sistemas de motivação e a reengenharia de processos de negócio; trajetórias tecnológicas: representadas pelo uso de tecnologias capazes de influenciar o processo de produtos e processos, como ferramentas de internet e demais tecnologias da informação e comunicação (TICs); trajetórias institucionais: estão ligadas às tendências evolutivas das regulamentações e das instituições políticas, sendo que os autores consideram as mudanças na economia e os programas de pesquisa exemplos típicos; trajetórias sociais: a evolução das regras e das convenções sociais, tais como a conscientização ecológica e ambiental.

As forças externas são representadas pelos agentes definidos por Sundbo e Gallouj (1998) como indivíduos ou organizações cujos comportamentos sejam importantes para a empresa comercializar seus serviços e por consequência influenciar as atividades inovadoras e estão divididos em: clientes: representam os atores de maior relevância, pois mantêm um relacionamento mais intenso com o prestador de serviços; competidores: a coopetição entre os competidores em serviços contribui para o processo de inovação; governo: assume múltiplos papéis, atuando como cliente, fornecedor, competidor ou regulamentador; e fornecedores: o grau de dependência de fornecedor, dependendo a atividade de serviços, influencia fortemente o processo de inovação.

\subsection{Barreiras à inovação}

A inovação pode ser vista como um processo que ocorre em diversas fases, partindo de algum problema específico identificado que passa, necessariamente, pela sistematização das dificuldades existentes, a percepção da prática inovadora e dos processos políticos que envolvem a aceitação da inovação por parte dos diversos agentes envolvidos no processo (LOUNSBURY, CRUMLEY, 2007). Além desses fatores, a criação de inovação precisa transpor barreiras inerentes ao processo conforme 
descrito por Sheth e Ram (1987): expertise: caracterizado pelo risco da especialização demasiada que pode colocar os indivíduos na zona de conforto operacional dificultando a busca por inovações; processos: o entendimento dos processos da organização com já devidamente ajustados e adequados às aplicações reduzindo a intenção de causar mudanças; recursos: a indisponibilidade de recursos financeiros, materiais ou humanos para a implantação de processos inovadores pode constituir-se em barreira a inovação; legislação e normas: o conjunto de regulamentações para um setor ou tipo de atividade específica por constituir um tipo de barreira ou agente de desaceleração do processo de inovação; e novos mercados e produtos: a limitação à entrada em novos mercados ou desenvolvimento de novos produtos pode limitar o processo de inovação.

Na concepção de Coriat e Weinstein (2002), é possível falar de uma visão organizacional da inovação na medida em que a análise do processo da inovação e das condições do êxito da inovação são tratados, considerando a visão interna das empresas representada pela suas estruturas, os modos de coordenação entre os grupos e entre as subunidades, os mecanismos de incentivo e o sistema de governança. Para este conceito dois principais temas surgem como relevantes: a empresa, como o agente central da inovação; e a variável organizacional como fator chave na capacidade de uma empresa para inovar. A formação de alianças estratégicas ou redes interorganizacionais pode agregar as competências necessárias a uma empresa focal para o desenvolvimento de inovações. Inovar requer, além da disponibilidade da organização, a equalização dos recursos, capacitações e competências às necessidades do processo inovador.

\subsection{Inovação em Serviços}

O desenvolvimento rápido de novos produtos associados à inovação tornou-se fundamental nas mais importantes indústrias globais, tendo como objetivo alcançar ou sustentar vantagens competitivas (DASCHS, EBERRSBERGER, LÖÖF, 2008; SIMMIE, STRAMBACH, 2007). No entanto, o crescimento econômico não se restringe ao setor industrial como ocorria até recentemente, pois novas oportunidades de negócio surgiram no setor de serviços. As tecnologias da informação e da comunicação são as grandes responsáveis por este crescimento, e no Brasil o setor de serviços é responsável por mais de 63\% do Produto Interno Bruto (IBGE, 2011), nas economias avançadas os serviços representam mais de $70 \%$ da riqueza (GALLOUJ, SANSON, 2007). O interesse pelo setor de serviços tem crescido exponencialmente a partir de constatações da sua força no desenvolvimento e na integração econômica tanto nas economias emergentes quanto nas avançadas. $\mathrm{O}$ crescimento ocorre não exclusivamente pela sua função geradora de emprego e renda, mas também pela importância dos 
serviços na interface com a indústria como forma de incrementar o progresso técnico e a criação da riqueza social (BERNARDES, ANDREASSI, 2007).

Tendo em vista as novas oportunidades criadas no setor de serviços percebe-se que um dos fenômenos mais notáveis nas últimas décadas na economia mundial é o crescimento deste setor. Esse fenômeno passou a ser conhecido como a Terceira Revolução Industrial, na qual as oportunidades de crescimento e inovação deslocaram-se do setor industrial para o de serviços (AMATO NETO, 2007). Esta nova dinâmica engloba também serviços públicos como transporte, telefonia, segurança e saúde.

$\mathrm{Na}$ maioria dos estudos, os serviços tendem a serem intangíveis, heterogêneos, produzidos simultaneamente e perecíveis. A inovação nos serviços envolve, na maior parte dos casos, mudanças pequenas e incrementais nos processos e nos procedimentos, sendo essas mais acessíveis por não apresentarem altos custos de $\mathrm{P} \& \mathrm{D}$, pois as empresas de serviços não gastam com patentes e compra de licenças, investindo basicamente na aplicação de tecnologias na operacionalização do processo (JONG, VERMEULEN, 2003). Smith (2008) declara que a inovação começa com a observação e a experiência. Seu processo começa pela visão de algo valioso, oriundo de uma nova tecnologia, de um novo processo ou de uma nova aplicação de algo já existente.

Sendo o setor de serviços de extrema diversidade, inovações nesta área distinguem-se na sua organização e na execução das formas mais tradicionais de inovação (HIPP, 2008; DJELLAL, GALLOUJ, 2007). De acordo com Gallouj e Sanson (2007), as diferenças em termos de inovação são mais significativas no cerne dos serviços do que entre certos setores industriais. Pesquisas de inovação são relativamente recentes, e a história da pesquisa de inovação na indústria de serviços é ainda mais recente (HAMDANI, 2007; JACOBY, RODRIGUEZ, 2007). Somente na sociedade pós-industrial as inovações em serviços começaram a ter destaque (SIMMIE, STRAMBACH, 2007; CAMACHO, RODRIGUEZ, 2005).

Analisar as inovações no setor de serviços torna-se tarefa de difícil execução em razão de dois fatores principais definidos por Gallouj e Weinstein (1997): as teorias de inovação foram desenvolvidas pela aplicação de implementos tecnológicos em atividades manufatureiras; e as características específicas das atividades de serviços dificultam a elaboração de modelos para atender a todas as mudanças que podem caracterizar as inovações.

A teoria do "ciclo reverso de produto" criada por Barras (1986) propõe inovações em serviços pela aplicação de tecnologias da informação em três níveis: aplicação de nova tecnologia com o objetivo de aumentar a eficiência e a eficácia na prestação de serviços preexistentes (na qual predominam inovações de ordem incremental de processos); inovações de processos são aplicadas com base em tecnologias para melhorar a qualidade dos serviços; e inovações que criam novos serviços ou 
transformam serviços existentes. Essa teoria proposta por Barras (1986) foi elaborada no sentido contrário ao ciclo de implementação de tecnologias para fabricação de produtos no setor industrial. Tal enfoque teórico é, basicamente, aplicado para inovações baseadas em tecnologia aplicada a atividades de serviços na qual é feita a distinção entre a inovação em produto e inovação em processos. No entanto, o produto e seu processo estão fortemente correlacionados no setor de serviços e nem sempre é possível fazer a distinção, sendo que as inovações poderão ocorrer simultaneamente no produto e no processo.

A evolução das teorias que envolvem inovações em serviços pode ser representada pelo enfoque proposto por Sundbo e Gallouj (1998), que divide as inovações em serviços em cinco categorias: inovação de produto: a introdução de um novo produto no mercado implicará serviços atrelados a este produto (inovação ocorre exogenamente); inovação de processo: ocorre quando são modificados processos para produzir ou prestar um determinado serviço (endógena); inovação organizacional: a organização modifica ou adapta sua estrutura, o que impacta em seu gerenciamento; inovação de mercado: o surgimento de novos segmentos ou mesmo de novos serviços em um mercado específico; e inovação ad hoc: a criação de soluções para determinados problemas específicos de um cliente (customização).

\subsection{Regulação do transporte público}

Os sistemas regulares de transporte coletivo de passageiros (empresas concessionárias) têm sua competitividade constantemente ameaçada pela redução do número de passageiros transportados, causada pela migração de passageiros para transportes alternativos e pela emergência de novos modelos sociais. Igualmente, a estabilização da economia, nas últimas décadas, possibilitou o incremento de renda e, juntamente com o crescimento do setor automotivo e as novas políticas públicas para este setor, proporcionou o acesso das camadas mais populares ao primeiro veículo automotor (ARAGÃO et al, 2000).

No Brasil as concessões públicas são regulamentadas pela lei 8.987/95, como previsto no artigo 175 da Constituição Federal, que dispõe sobre a prestação de serviços públicos. A regulação tem como objetivo aumentar a eficiência dos mercados correspondentes, tornando-os atrativos e mais estáveis, sem inibir a concorrência nesses mercados, criando situações monopolistas (POSSAS, PONDE, FAGUNDES, 1997). A regulação de serviços públicos busca aumentar a eficiência e eficácia da prestação destes serviços em setores nos quais a concorrência poderia interferir na qualidade dos serviços oferecidos à população (CAMACHO, 2004). 
O transporte público tem utilizado os mecanismos de regulação nas situações de monopólios naturais, devido aos custos e à complexidade envolvidos no processo de operação de linhas de transporte público (ARAGÃO, SANTOS, 2000). O Estado trabalha como um facilitador para tornar as economias viáveis e competitivas nas áreas que envolvem infraestruturas e serviços públicos, seja pela sua função de fomento à economia como um todo, seja pela influência na composição dos preços dos produtos. Os itens de infraestrutura e serviços públicos de um país são essenciais para garantir o bemestar social, reduzindo as desigualdades sociais e garantindo maior coesão e integração nacional (SANTOS, 2000).

O modelo brasileiro de concessão de serviços públicos de transporte coletivo baseia-se no modelo de remuneração empresarial no qual as empresas obtêm suas receitas da exploração do negócio de transportes públicos. Privilegia-se no modelo a eficiência e a eficácia dos serviços, que são é supervisionados e normatizados pelos órgãos do Estado, que buscam manter o equilíbrio econômico do sistema incentivando os ganhos de competitividade, tendo como fim atender as demandas da sociedade pelo transporte de acesso livre e universal (GOMIDE, ORINOCO FILHO, 2000). Não basta ao Estado conceder a exploração dos serviços públicos, faz-se necessária a exigência de qualidade no atendimento prestado à população.

No setor de transporte público, os monopólios regulamentados são uma solução para questões operacionais que em situações de livre concorrência poderiam aumentar a ineficiência e ineficácia do sistema, visto que empresas em mercados de alta competitividade buscam reduzir custos e aumentar margens de lucro que poderiam ocorrer em detrimento da qualidade do serviço. Além disso, a necessidade do funcionamento do transporte público em dias e horários não lucrativos pode causar o desinteresse das empresas transportadoras de linhas e horários de baixa lucratividade, que poderiam ser abandonadas, deixando parcelas da população sem disponibilidade do serviço (SOUZA JÚNIOR, 2006; CAMACHO, 2004).

\section{Modelo de desenvolvimento da pesquisa}

O presente estudo foi desenvolvido a partir de casos múltiplos em quatro unidades de análise situadas no estado do rio grande do sul, que segundo Yin (2001) cada unidade de análise trata-se de casos individuais e o conjunto da pesquisa é obtida pela conversão de vários casos em um caso único que sintetiza o conjunto de casos estudados. Para o desenvolvimento do mesmo, foram sistematizados e analisados dados primários e secundários (entrevistas e análise documental), cujos casos foram denominados de $\alpha, \beta, \gamma$ e $\Omega$ (Quadro 1). A pesquisa teve caráter qualitativo de natureza exploratória 
descritiva. esse modelo é indicado devido ao enfoque exploratório ser apropriado para aprofundar a compreensão dos aspectos que compõem o cenário organizacional, palco das interações estudadas (HAIR, et al, 2005) e identificar variáveis que não sejam conhecidas ou não estejam totalmente definidas (COOPER, SCHINDLER, 2003). Na abordagem descritiva há a preocupação com a explicação do que efetivamente foi presenciado.

Nos casos estudados havia pouca ocorrência de trabalhos específicos que permitissem a definição a priori das variáveis, fazendo-se necessário a coleta de dados qualitativos e análise documental para identificá-las. Outra razão para a pesquisa ser de natureza exploratória é a especificidade do tema em estudo ser dotado de intangibilidade, o que torna restritivo formular hipóteses precisas e operacionalizáveis a priori (GIL, 2002). Dados de natureza qualitativa extrapolam as fronteiras rigidamente delineadas pelos instrumentos quantitativos de coleta de dados, permitindo o aprofundamento dos estudos e a descoberta de novas variáveis e aspectos intangíveis que podem ser relatados a partir da combinação de enfoques metodológicos (HAIR, et al, 2005).

Em razão de a pesquisa haver sido realizada em diferentes unidades de análise do estado do rio grande do sul, optou-se por utilizar o estudo de casos múltiplos, que é considerado mais convincente e permite a comparação de diferentes realidades. a lógica subjacente ao uso de estudo de casos múltiplos é igual ao caso único e ambos devem ser cuidadosamente selecionados de forma a: (a) prever resultados semelhantes (uma replicação literal); ou (b) produzir resultados contrastantes apenas por razões previsíveis (uma replicação teórica). As provas conclusivas de casos múltiplos são consideradas mais convincentes e o estudo global é visto, por conseguinte, como sendo mais robusto (YIN, 2001). Apesar de localizarem-se em diferentes locais e serem regidos por distintas legislações, nas quais o poder concedente é formado por órgãos públicos não interligados, as realidades são semelhantes.

O presente estudo baseou-se na metodologia de casos múltiplos nomeados como Casos $\alpha, \beta, \gamma \mathrm{e}$ $\Omega$ a fim de proteger a identidade dos entrevistados e das empresas e órgãos públicos objeto do estudo (Quadro 1). Ressalta-se que cada caso é regido por distintas legislações estabelecidas pelo Poder Concedente, ratificado por Yin (2001) quando o mesmo referencia possíveis variâncias entre casos que forem objeto de estudo. 
Quadro 1 - Casos analisados

\section{CASOS ANALISADOS}

\begin{tabular}{|l|l|}
\hline Caso & Descrição \\
\hline $\mathbf{A}$ & $\begin{array}{l}\text { Cidade localizada no centro do Estado do Rio Grande do Sul com cerca de 300.000 habitantes fixos, } \\
\text { de economia baseada no setor de serviços públicos, em especial no ensino universitário e nas forças } \\
\text { armadas. As empresas de transporte público desta cidade realizam o transporte de passageiros no } \\
\text { limite urbano do município e são supervisionadas pela prefeitura municipal. }\end{array}$ \\
\hline $\mathbf{B}$ & $\begin{array}{l}\text { Abrange mais de } 20 \text { municípios no entorno da capital do Estado do Rio Grande do Sul que } \\
\text { concentram uma população aproximada de } 1.500 .000 \text { habitantes e de economia bastante } \\
\text { diversificada. As empresas de transporte público selecionadas para este estudo realizam o transporte } \\
\text { de passageiros em seus municípios e também destes para a capital do Estado. Para fins desta pesquisa } \\
\text { foram analisadas as empresas que se reuniram em um consórcio, com intermédio de uma Associação. }\end{array}$ \\
\hline $\boldsymbol{\Gamma}$ & $\begin{array}{l}\text { Cidade com maior população do Rio Grande do Sul com cerca de 1.400.000 habitantes e economia } \\
\text { predominante no setor de varejo e serviços. Os transportadores de passageiros desta cidade realizam o } \\
\text { transporte interno no município e operam de forma consorciada desde o final da década de 1990. São } \\
\text { três consórcios que abrangem as regiões sul, norte, sudeste-leste e mais uma empresa pública que faz } \\
\text { a interligação dos eixos com as linhas transversais. }\end{array}$ \\
\hline $\boldsymbol{\Omega}$ & $\begin{array}{l}\text { Esta cidade possui a segunda maior população e segundo maior PIB do Estado do Rio Grande do Sul } \\
\text { e constitui-se em importante polo metal-mecânico e de turismo. No município opera apenas uma } \\
\text { empresa sob regulação municipal que iniciou a implantação do sistema de bilhetagem em 2001. }\end{array}$ \\
\hline
\end{tabular}

Para facilitar a compilação dos dados de natureza qualitativa foi utilizada Análise de Conteúdo a posteriori por acreditar que esta metodologia de investigação possibilite descrever e interpretar todas as classes de texto (BARDIN, 1977). Utilizando como base Bardin (1977), Bauer e Gaskel (2002), Godoy (1995), Moraes (1999), Richardson (1999) e Simões (1991) a Análise de Conteúdo a posteriori foi realizada em cinco etapas: a) delineamento: analisando os dados empíricos coletados foram construídas as categorias de análise; b) pré-análise: consistiu da análise prévia dos materiais coletados; c) tratamento dos dados: extraiu-se dos dados palavras-chave que representassem o conteúdo do texto; d) julgamento da validade: as análises foram validadas pela relação teoria versus dados empíricos; e) agrupamento das categorias: as categorias foram agrupadas de forma a compilar os dados empíricos criando uma síntese dos dados coletados (Figura 1).

Figura 1 - etapas da Análise de Conteúdo

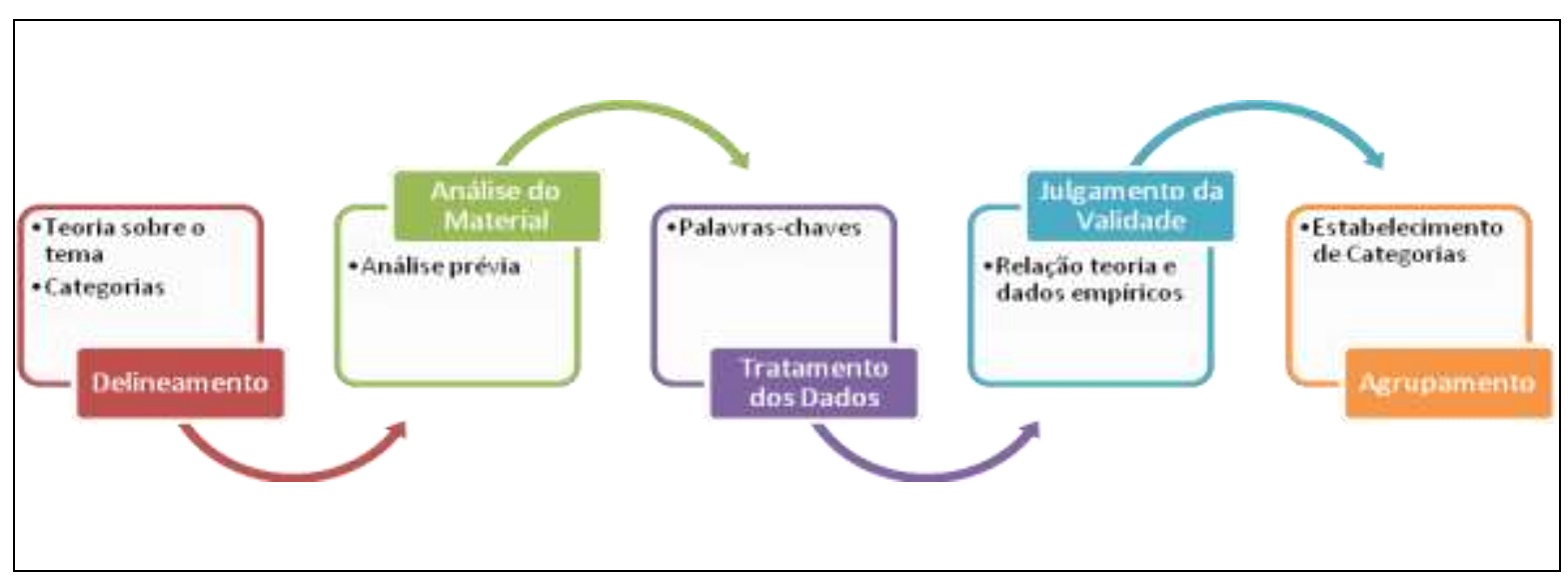


A partir da análise prévia dos dados empíricos definiu-se neste estudo as seguintes categorias: a) regulação: papel exercido pelos órgão reguladores na implementação da bilhetagem; b) bilhetagem eletrônica: descrição das funcionalidades do sistema; c) processos ex-ante a bilhetagem: mapeamento de etapas dos processo de compra, venda e utilização de passagens antes da implementação da bilhetagem; d) processos ex-post a bilhetagem: mapeamento dos processos de compra, venda e utilização de passagens após a implementação da bilhetagem; e) mudanças ex-post: mapeou-se as mudanças ocorridas após a implementação do sistema que constituem-se nos impactos e melhorias proporcionados pela bilhetagem.

As palavras-chave da Análise de Conteúdo foram agrupadas nas categorias selecionadas a posteriori, de forma a possibilitar a verificação das melhorias inovadoras nos casos selecionados (Figura 2). Utilizou-se esta técnica para permitir apresentar ao leitor resultados mais concisos sem a necessidade de longas descrições tornando mais objetiva a redação a fim de facilitar sua compreensão.

Figura 2 - exemplo da formação de categoria

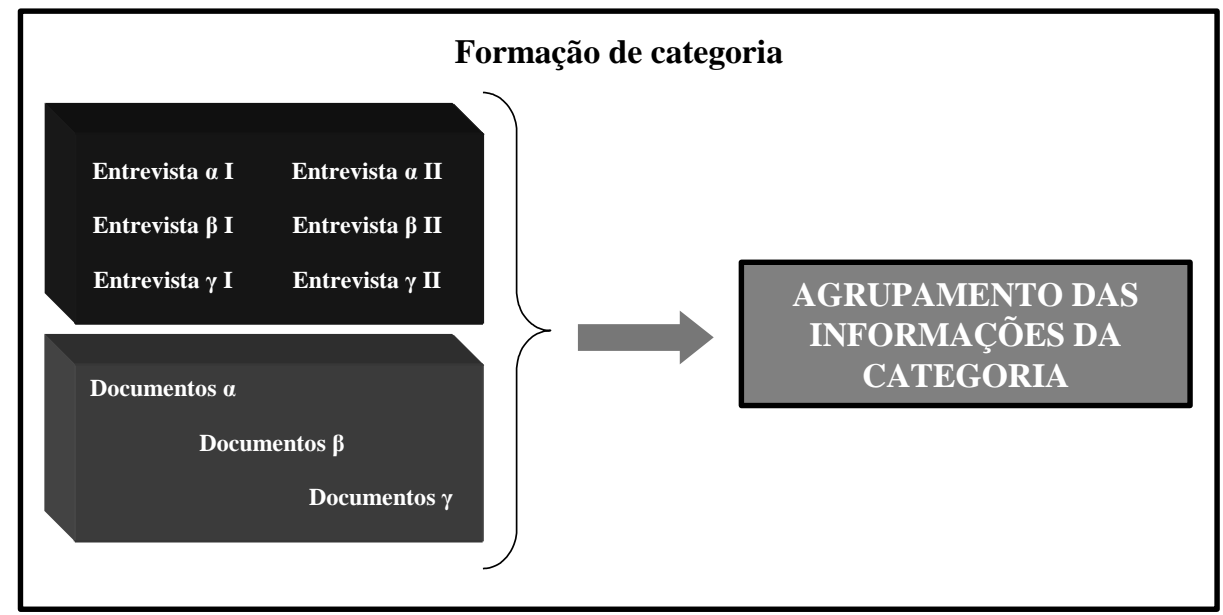

Após serem agrupadas em cada categoria, as informações foram descritas e interpretadas de forma a obterem-se as melhorias proporcionadas pelo sistema de bilhetagem eletrônica cruzando as informações dos casos selecionados. Por fim as melhorias proporcionadas são analisadas ante o conceito de inovação desenvolvido para mensurar inovação. No presente estudo foram realizadas entrevistas com gestores das empresas e órgãos públicos analisado que foram descritos no Quadro 2. 


\begin{tabular}{|l|l|}
\hline \multicolumn{1}{|c|}{ Unidade de análise } & Entrevistados \\
\hline Caso $\alpha$ & $\begin{array}{l}\text { Gerente executivo da Associação dos transportadores; Presidente da Associação; } \\
\text { Representante do Poder Concedente. }\end{array}$ \\
\hline Caso $\boldsymbol{\beta}$ & $\begin{array}{l}\text { Gerente executivo da Associação dos transportadores; Gerente de TI do Consórcio Gestor; } \\
\text { Gerente do Consórcio Gestor; Gerente operacional da Empresa Transportadora 1; Gerente } \\
\text { operacional da Empresa Transportadora 2; Diretor executivo da Empresa Transportadora 2; } \\
\text { Diretor do Poder Concedente. }\end{array}$ \\
\hline Caso $\gamma$ & $\begin{array}{l}\text { Gerente executivo da Associação dos transportadores; Diretor do Poder Concedente; Gerente } \\
\text { operacional da Empresa transportadora 1; Gerente operacional da Empresa transportadora 2; } \\
\text { Gerente operacional da Empresa transportadora 3. }\end{array}$ \\
\hline Caso $\Omega$ & $\begin{array}{l}\text { Diretor do Poder Concedente; Gerente de transporte público do Poder Concedente; Gerente } \\
\text { operacional da empresa transportadora; Gerente de tecnologia da empresa transportadora } \\
\text { (nesse caso somente existia uma empresa concessionários do transporte público urbano). }\end{array}$ \\
\hline
\end{tabular}

A combinação das diferentes fontes de dados empíricos possibilitou escrever um relatório de casos cruzados e compará-lo com as características de inovação destacadas na revisão bibliográfica como forma a responder adequadamente a questão de pesquisa proposta. Concluídas as análises de dados qualitativos foi construída a comparação entre os fatores que envolvem a inovação e os resultados da pesquisa empírica, de forma a responder os objetivos propostos. Esta etapa da pesquisa foi executada comparando-se cada fator com os resultados obtidos e a partir desta comparação foram elaboradas as considerações deste trabalho.

\section{Contextualização e análises}

O setor de transporte público urbano em cidades-polo do Estado do Rio Grande do Sul tem sido impelido à busca pela inovação a partir da utilização de novas tecnologias, pois vêm sofrendo impactos econômicos causados por transformações nas demandas de passageiros, crescimento das exigências dos usuários e do Poder Concedente, (corresponde aos órgãos públicos que regulamentam o serviço de transporte coletivo urbano e interurbano representados por Secretarias Municipais de Transporte, empresa pública destinada a regulamentar o serviço de transporte urbano e interurbano e agência regulatória em nível estadual). Mudanças na configuração das cidades, como oportunidades de trabalho em locais fora dos tradicionais centros econômicos, o trabalho em casa (homeoffice), o aumento e as facilidades para aquisição de veículos para transporte individual, o crescimento dos deslocamentos a pé, os engarrafamentos, questões ambientais e de responsabilidade social, cujos dos fatores passaram a serem considerados no modus operandi do transporte de pessoas. Esses fatores permitem citar o crescimento da necessidade de ganhar eficiência e eficácia operacional em um setor econômico que possuía uma situação relativamente estável. 
Nesse cenário, destacam-se os sistemas de controle na compra, venda e utilização de passagens, representados pela bilhetagem eletrônica, que foi desenvolvida como uma evolução dos cartões de crédito com tarja magnética, devido a preocupações com ineficiências na gestão das informações e controle de operações de transporte público. A plataforma tecnológica realiza cadastros dos usuários, controle das operações de venda de vale-transporte, carga de créditos a bordo do ônibus e emissão dos relatórios diários permitindo o monitoramento preciso dos dados.

A implantação do sistema extingue o vale-transporte de papel ou mesmo de fichas plásticas existindo apenas o crédito em Reais que poderá ser utilizado em qualquer das empresas que operam com a mesma plataforma. Os créditos, após serem utilizados pelos usuários nos ônibus, são encaminhados às empresas de transporte nas quais foram gastos em Reais via compensação bancária pelo controle central do sistema. O cartão dos usuários mantém as informações neles armazenadas e sua leitura é realizada em equipamentos específicos, chamados de validadores, que estão instalados ao lado da catraca do ônibus e a destravam mediante o pagamento com o cartão, tendo como foco restringir as ineficiências dos sistemas tradicionais do vale-transporte.

Nas cidades abrangidas por este estudo, a implementação do sistema de bilhetagem eletrônica exigiu a formação de Consórcios Gestores entre as empresas transportadoras devido à dimensão do investimento e dificuldades comuns a todas as empresas envolvidas no processo de implementação e gerenciamento da bilhetagem. Os Consórcios Gestores ficaram responsáveis pelo desenvolvimento do sistema que passou a dar suporte à operação da bilhetagem associada a equipamentos de controle. A plataforma tecnológica realiza o cadastro dos usuários, controla as operações de venda de créditos, realiza carga de cartões a bordo, emite informações e relatórios gerenciais.

Para realizar as análises finais os dados foram divididos por categoria e compilados visando ao somatório do conhecimento capturado e sistematizado da pesquisa. Cada categoria foi analisada utilizando-se de palavras-chave representativas dos dados empíricos de cada caso estudado (Análise de Conteúdo), e na sequência os dados foram sistematizados de forma a representar os casos analisados neste trabalho demonstrando as características inovadoras dos efeitos obtidos com a bilhetagem eletrônica. Cada categoria destacada nesta análise consiste em uma síntese dos dados coletados nos três casos estudados e assim foram descritas neste artigo, pois os textos provenientes deste processo de análise são muito longos para serem apresentados detalhadamente em um artigo científico.

\subsection{Regulação}


Quadro 3 - cruzamento da categoria regulação

\begin{tabular}{|l|l|}
\hline \multicolumn{2}{|c|}{ Cruzamento da categoria: Regulação } \\
\hline Caso $\alpha$ & Poder Concedente, cria, aplica, legislação, punições. \\
\hline Caso $\beta$ & Poder Concedente, normas, limitações geográficas. \\
\hline Caso $\gamma$ & $\begin{array}{l}\text { Poder Concedente, regras, estudos técnicos; } \\
\text { bilhetagem. }\end{array}$ \\
\hline Caso $\boldsymbol{\Omega}$ & $\begin{array}{l}\text { Poder Concedente; demandas técnicas, conselho de } \\
\text { transporte. Bilhetagem }\end{array}$ \\
\hline
\end{tabular}

O Poder Concedente (órgãos reguladores) elabora a legislação do transporte público fiscalizando as empresas permissionárias e aplicando punições conforme a legislação vigente e as normas elaboradas a partir de estudos técnicos ou demandas sociais. Tais demandas passam por avaliação no Poder Concedente e após ajustadas e aprovadas por um conselho transformam-se em normas que devem ser cumpridas pelas empresas transportadoras.

As empresas transportadoras operam em regiões delimitadas e com legislação própria havendo variações em cada cidade. A implantação da bilhetagem foi influenciada diretamente pelo Poder Concedente nos casos analisados devido à necessidade de aperfeiçoar as formas de controle sobre a operação, que até então geravam dados pouco precisos dificultando a fiscalização. O desenvolvimento dos sistemas de bilhetagem eletrônica ficou a cargo das empresas transportadoras com apoio do Poder Concedente, sendo que os transportadores são responsáveis pelos equipamentos e programas instalados e pela manutenção, atualização e criação de soluções para as dificuldades que surgirem.

\subsection{Bilhetagem eletrônica}

Quadro 4 - cruzamento da categoria Bilhetagem eletrônica

\begin{tabular}{|l|l|}
\hline \multicolumn{2}{|c|}{ Cruzamento da categoria: Bilhetagem eletrônica } \\
\hline Caso $\boldsymbol{\alpha}$ & $\begin{array}{l}\text { Integração; redução de custos; segurança; dados estatísticos; auditar; } \\
\text { desafio redução de custos; dados precisos }\end{array}$ \\
\hline Caso $\boldsymbol{\beta}$ & $\begin{array}{l}\text { Soluções para fraudes, comércio ilegal, atualização tecnológica e } \\
\text { qualificação dos dados; novas necessidades; múltiplas tarifas } \\
\text { dificuldade; complexidade }\end{array}$ \\
\hline Caso $\boldsymbol{\gamma}$ & $\begin{array}{l}\text { Salto tecnológico; referência, profissionalizar, gestão; otimizar o } \\
\text { desempenho; eliminação, fraudes, falsificações; sistema sob demanda, } \\
\text { capacidade de adaptação; implementada, etapas, tipo de usuário }\end{array}$ \\
\hline Caso $\Omega$ & $\begin{array}{l}\text { Mudança cultural; investimentos elevados; informar os usuários; } \\
\text { adaptação rapidamente; redução de dinheiro; eliminação das fichas; }\end{array}$ \\
\hline
\end{tabular}

A bilhetagem eletrônica foi desenvolvida como uma evolução dos cartões de crédito com tarja magnética, devido a preocupações com ineficiências na gestão das informações e controle de operações de transporte público. A plataforma realiza o cadastro dos usuários, controla as operações de venda de 
vale-transporte, realiza a carga de créditos a bordo do ônibus e emite os relatórios gerenciais permitindo o monitoramento mais preciso dos dados.

A implantação do sistema extinguiu o vale-transporte de fichas plásticas, existindo apenas o crédito em Reais que poderá ser utilizado em qualquer das empresas que operam com a mesma plataforma. Os créditos, após serem utilizados pelos usuários nos ônibus, são encaminhados às empresas de transporte nas quais foram gastos em Reais via compensação bancária, pelo controle central do sistema. O cartão dos usuários mantém as informações neles armazenadas e sua leitura é realizada em equipamentos específicos, chamados de validadores, que estão instalados ao lado da catraca do ônibus e a destravam mediante o pagamento com o cartão. Estes sistemas de bilhetagem eletrônica têm como foco diminuir as ineficiências dos sistemas tradicionais de vale-transporte.

Nas cidades abrangidas por este estudo, a implementação do sistema de bilhetagem eletrônica exigiu a formação de Consórcios Gestores para o sistema entre as empresas transportadoras devido à dimensão do investimento e dificuldades comuns a todas as empresas envolvidas no processo de implementação e gerenciamento da bilhetagem. Os Consórcios Gestores ficaram responsáveis pelo desenvolvimento do sistema que passou a dar suporte à operação da bilhetagem associada a equipamentos de controle. A plataforma tecnológica realiza o cadastro dos usuários, controla as operações de venda de créditos, realiza carga de cartões a bordo, emite informações e relatórios gerenciais.

\subsection{Processos ex-ante a bilhetagem}

Quadro 5 - Cruzamento da categoria processos ex-ante a bilhetagem

\begin{tabular}{|l|l|}
\hline \multicolumn{2}{|c|}{ Cruzamento da categoria processos ex-ante a bilhetagem } \\
Caso $\boldsymbol{\alpha}$ & $\begin{array}{l}\text { acerto, valores; guichê; fichas, transferidas, Associação, confere, } \\
\text { reaproveita,; dados, acerto, tabulados, relatórios; manual, imprecisões, } \\
\text { impossibilita, dimensionamento }\end{array}$ \\
\hline Caso $\boldsymbol{\beta}$ & $\begin{array}{l}\text { passagens, via física, loja, filas,; tarifas seccionadas, complexidade; cobrador, } \\
\text { armazenava, vias físicas, entregava, guichê; manualmente, relatórios, } \\
\text { compilados, totalização; logística, comércio ilegal, utilização indevida; } \\
\text { dificuldades, controle, dados, erros }\end{array}$ \\
\hline Caso $\gamma$ & $\begin{array}{l}\text { passagens, loja, via física; cobradores, dinheiro, isentos identidade, } \\
\text { manualmente; valores, entregues, boletim, não discriminava, valores bancos, } \\
\text { vales-transporte e passagens escolares empresas }\end{array}$ \\
\hline Caso $\Omega$ & $\begin{array}{l}\text { Pessoas e recursos; manual, erros, roubo, falsificação, dinheiro, banco, } \\
\text { carros-forte }\end{array}$ \\
\hline
\end{tabular}

O sistema antigo de compra, venda e utilização de passagens caracterizava-se pela comercialização do vale-transporte e passagem escolar (fichas ou vales em papel) em lojas próprias das Associações de Transportadores. Os cobradores dos ônibus, por sua vez, recebiam pagamentos em 
dinheiro e em fichas plásticas ou vales-transportes em papel, enquanto que os idosos e demais isentos apresentavam apenas a identidade, sendo contabilizados manualmente e, em alguns casos, nem passavam a roleta. A síntese dos processos ex-ante foi descrita no Quadro 6.

Quadro 6 - processos ex-ante

\begin{tabular}{|c|l|}
\hline \multicolumn{2}{|c|}{ PROCESSOS EX-ANTE } \\
\hline Etapa & Descrição \\
\hline 1 & $\begin{array}{l}\text { Na sede ou lojas da Associação de transportadores urbanos de passageiros } \\
\text { são comercializados os vale-transporte, ou passagens escolares. }\end{array}$ \\
\hline 2 & $\begin{array}{l}\text { O vale-transporte, passagem escolar ou dinheiro são entregues ao cobrador } \\
\text { como pagamento da passagem. Os idosos e demais isentos apresentam } \\
\text { documentos comprobatórios do direito ao benefício. }\end{array}$ \\
\hline 3 & $\begin{array}{l}\text { Onibus retorna a garagem ao final do turno de trabalho do motorista e } \\
\text { cobrador. }\end{array}$ \\
\hline 4 & $\begin{array}{l}\text { Cobrador dirige-se ao caixa para realizar a entrega dos valores } \\
\text { correspondentes à movimentação do turno de trabalho. }\end{array}$ \\
\hline 5 & $\begin{array}{l}\text { Os vales-transportes, passagens escolares e dinheiro são colocados em um } \\
\text { carro-forte. }\end{array}$ \\
\hline 6 & $\begin{array}{l}\text { Os vales-transportes e passagens escolares são encaminhados para a } \\
\text { Associação que os reaproveita ou inutiliza. }\end{array}$ \\
\hline 7 & Os valores em dinheiro são encaminhados para um banco. \\
\hline 8 & Os dados referentes às movimentações diárias são digitados. \\
\hline 9 & Os dados de movimentação de passageiros são armazenados e processados. \\
\hline 10 & $\begin{array}{l}\text { As empresas transportadoras e o Poder Concedente recebem os dados de } \\
\text { movimentação diária, semanal e mensal para efetuar seus controles. }\end{array}$ \\
\hline
\end{tabular}

Os valores recolhidos eram entregues pelo cobrador ao final de sua jornada a um responsável das empresas transportadoras, juntamente com um boletim do total de passageiros transportados (números registrados nas catracas) que, no entanto, não discriminava o tipo de passageiro (isentos, pagantes, vale-transporte ou passagem escolar). Os valores recolhidos eram transportados até os bancos e os vales-transportes e passagens escolares ou fichas retornavam para as empresas.

\subsection{Processos ex-post bilhetagem}

Quadro 7 - Cruzamento da categoria processos ex-post a bilhetagem

\begin{tabular}{|l|l|}
\hline Caso $\boldsymbol{\alpha}$ & $\begin{array}{l}\text { Cruzamento da categoria: processos ex-post a bilhetagem } \\
\text { cobrador, equipamento, deposita, dinheiro; segurança, redução, dinheiro, planejamento, reduzindo } \\
\text { as ineficiências e ineficácias, sistema seguro; }\end{array}$ \\
\hline Caso $\boldsymbol{\beta}$ & $\begin{array}{l}\text { Bilhetagem, controlar efetivamente, relatórios, reduzir fraudes e eliminar as falsificações; dados, } \\
\text { processo eficiente e eficaz de gestão da informação, reduzindo custos, redução do tempo; cobrador } \\
\text { abre a linha, validador, encerramento, validador transmite dados computadores da empresa, central } \\
\text { do sistema; controle origem do passageiro; desafios, interoperabilidade, incompatibilidade, controle } \\
\text { das fraudes nas gratuidades, informações sobre o transporte ao usuário, bloqueio imediato do cartão, } \\
\text { multitarifa, atualização da tecnologia, locais para aquisição de cartões }\end{array}$ \\
\hline Caso $\gamma$ & $\begin{array}{l}\text { Bilhetagem, mudança paradigmática, profissionalização; controle total sobre a operação, integração } \\
\text { dispensando terminais; o fim do comércio ilegal e falsificações, evitar o mau-uso dos vale- } \\
\text { transporte e passagens escolares, créditos pela internet, segurança reduzindo valores em espécie, }\end{array}$ \\
\hline
\end{tabular}




\begin{tabular}{|l|l|}
\hline Caso $\Omega$ & $\begin{array}{l}\text { facilitou o troco, integração trem metropolitano, capacidade de adaptações;, interoperável; e melhor } \\
\text { dimensionamento das operações; desafios, GPRS, destinos de passagiros, interoperabilidade, } \\
\text { integração com o trem com redução tarifária, débito utilizando o celular, sistema de contingência }\end{array}$ \\
\hline $\begin{array}{l}\text { Melhor dimensionamento de operações, adaptação rápida dos usuários, baixo índice de } \\
\text { reclamações; permite integração, compra internet carga a bordo, redução filas, segurança, bloqueio } \\
\text { do cartão, 10 passagens dia. }\end{array}$ \\
\hline
\end{tabular}

Os processos ex-post foram descritos no Quadro 8 como forma de demonstrar as mudanças ocorridas após o implemento da bilhetagem as quais demonstraram racionalização de processos e possibilidades de efetuar operações que até então eram inviáveis.

Quadro 8 - Processos ex-post

\begin{tabular}{|c|c|}
\hline \multicolumn{2}{|r|}{ PROCESSOS EX-POST } \\
\hline Etapa & Descrição \\
\hline 1 & $\begin{array}{l}\text { Os créditos virtuais para o pagamento de passagens são comercializados nas } \\
\text { lojas da Associação e pela internet, os dados são enviados ao data center do } \\
\text { Consórcio Gestor. }\end{array}$ \\
\hline 2 & Cartões de usuários armazenam os créditos. \\
\hline 3 & $\begin{array}{l}\text { Os validadores possibilitam carga a bordo dos ônibus e armazenam os dados } \\
\text { de pagamentos de passagens e isentos que passaram a catraca. }\end{array}$ \\
\hline 4 & $\begin{array}{l}\text { Onibus retornam a garagem ao final do período de trabalho do motorista e } \\
\text { cobrador e os dados do validador são transmitidos automaticamente por } \\
\text { sistema sem fio ao servidor local. }\end{array}$ \\
\hline 5 & $\begin{array}{l}\text { Os valores recebidos pelo cobrador em dinheiro são entregues e os dados são } \\
\text { enviados ao servidor local. }\end{array}$ \\
\hline 6 & Os valores recebidos em espécie são encaminhados para um banco. \\
\hline 7 & $\begin{array}{l}\text { O servidor local envia os dados para o data center do consórcio gestor e } \\
\text { recebe deste atualizações de sistema e créditos comprados via internet. }\end{array}$ \\
\hline 8 & $\begin{array}{l}\text { Dados de movimentação são transmitidos para as empresas de transporte e } \\
\text { Poder Concedente. }\end{array}$ \\
\hline
\end{tabular}

O sistema de bilhetagem eletrônica, no primeiro momento, apresentou lacunas para fraudes que foram descobertas, como a utilização excessiva de passagens em um único dia por um mesmo usuário, o que gerou a limitação de uso diário correspondente a R \$ 10,00. A Bilhetagem Eletrônica permitiu o controle holístico sobre as operações e o uso do sistema informatizado causou impactos sociais e econômicos, tais como:

a) Fim do comércio ilegal: dificultou a falsificação de passagens, pois o comércio ilegal era o canal de vendas para os vales-transporte e passagens escolares falsificados. Este canal era também utilizado pelos trabalhadores para a venda dos vale-transporte que recebem das empresas nas quais exercem atividades. Dos trabalhadores desconta-se apenas parte do preço da passagem e o empregador arca com a maior parte dos custos. Devido a este fator, a bilhetagem também impactou economicamente as empresas em geral que poderão ter uma redução nos custos com funcionários uma vez que deixa de existir o vale-transporte como complemento de renda. Era comum ocorrer, embora 
este trabalho não tenha proposto mensurar este volume, a venda de vale-transporte por trabalhadores que substituíam o transporte coletivo por alguma forma de transporte individual e utilizavam o valetransporte como moeda no comércio informal. Com a bilhetagem esta utilização indevida torna-se de difícil exequibilidade, pois o crédito do vale-transporte é virtual e pessoal, não podendo ser transferido;

b) Criou dificuldades para a utilização indevida de benefícios como passagens escolares e descontos: anteriormente era possível a utilização indevida de benefícios devido a grande complexidade de controle do uso destes benefícios, pois o beneficiário não era em nenhum momento identificado. Com a bilhetagem passou a ser possível inclusive detectar possíveis fraudes mediante denúncias, comportamentos anormais de determinado usuário ou grupo de usuários (utilizações muito acima do razoável ou mesmo do permitido por lei), utilização de linhas distantes do endereço ou mesmo (com as tecnologias mais recentes) uso do cartão de outrem;

c) Redução das fraudes no uso de isenções: o advento das formas eletrônicas de controle de utilização e de identificação dificultam a utilização indevidas das isenções, pois as mesmas são destinadas a determinadas classes de funcionários públicos, fiscais, funcionários das empresas de ônibus, idosos e deficientes físicos e não podem ser utilizadas por terceiros. Devido à identificação eletrônica torna-se possível identificar fraudes e usos indevidos e bloquear os cartões; e

d) Redução de valores em espécie nos ônibus: com o fim dos vales-transporte e passagens escolares em via física reduziu-se a atratividade a assaltos nos ônibus, pelo menos no que se refere aos cobradores. Com isto é possível haver aumentado a segurança nos veículos podendo haver redução de perdas com assaltos que representa uma preocupação para autoridades públicas e para a sociedade.

Os próximos desafios para o sistema de bilhetagem eletrônica consistem na instalação de sistemas de GPRS para gerenciamento on-line da frota; a pesquisa de soluções para mapear os destinos de passageiros; a interoperabilidade com outras áreas, pois atualmente existem diferenças de software e hardware que incompatibilizam os sistemas; a integração com o trem com redução tarifária; a realização de débito de créditos utilizando o celular; a construção de um sistema de contingência que permita manter a operação em funcionamento mesmo em caso de falhas de grande porte do sistema principal.

\subsection{Melhorias da bilhetagem}

As melhorias da bilhetagem se traduzem pela capacidade do sistema de eliminar o comércio ilegal, fornecer dados qualificados, controlar o uso de benefícios, reduzir fraudes e falsificações, qualificar processos, aumentar a segurança, possibilitar a integração entre sistemas de transporte, 
reduzir custos, racionalizar a utilização de pessoal e possibilitar concessão de descontos na integração entre linhas.

Retomando o conceito de inovação adotado por este trabalho: inovação é o efeito causado por algum novo meio tecnológico, novo pensamento, novo conhecimento, nova ideia, nova forma de proceder aplicados em algo novo ou pré-existente que causa transformações benéficas para produtos, serviços, pessoas, organizações ou sociedade e que tenha resultados multifacetados e perceptíveis como inovadores. A partir deste conceito tem-se que as características inovadoras da bilhetagem se traduzem pelas melhorias que proporcionaram para as empresas transportadoras, para o Poder Concedente, os usuários e as empresas em geral (o termo "empresas em geral” se refere a toda organização comercial ou não que concede o benefício de vale-transporte a seus colaboradores).

Os efeitos característicos de uma inovação estão em consonância com os resultados da bilhetagem nos casos analisados fazendo deste sistema uma forma de se alcançar a inovação. Seguindo os preceitos escolhidos para este trabalho é pertinente reforçar que são inovadores os efeitos causados pela bilhetagem e não o sistema per se. A bilhetagem é um meio para se alcançar à inovação e não uma inovação per se. Significa dizer que o mesmo sistema e com as mesmas funcionalidades, pode não ser inovador em outro contexto no qual atuem outras empresas ou de localidades diferentes das pesquisadas.

Aspectos relacionados às melhorias proporcionadas pela bilhetagem devem ser ressaltados devido a sua capacidade transformadora, a exemplo do gerenciamento adequado das informações, que fornecem suporte para uma gestão mais eficiente e eficaz do transporte público nos casos analisados tanto para as empresas transportadoras quanto para o Poder Concedente. Ambos passaram a 'enxergar' a realidade das operações, pois ex-ante a bilhetagem, devido à grande possibilidade de erros nos processos, os dados foram considerados imprecisos e após a bilhetagem houve um aumento na quantidade de passageiros transportados tanto isentos como pagantes e eventuais reduções em categorias com direito a benefícios, segundo dados do Poder Concedente. Tais percepções ratificam a eficiência e eficácia da bilhetagem eletrônica na qualificação dos controles.

Outro aspecto que merece destaque é o fim do comércio ilegal que foi utilizado durante longo período para colocar no mercado falsificações de passagens e fomentar a venda de vale-transporte por trabalhadores. Este último item causava o mau-uso de um benefício garantido por lei ao trabalhador, onerando o empregador com despesas que poderiam ser evitadas. Tal situação também pode incitar uma discussão sobre aspectos morais e éticos das relações de trabalho, no entanto esta pesquisa não tem enfoque nesta discussão podendo deixá-la para outros campos das ciências sociais. Eliminar a comercialização de passagens impactou também a sociedade porque havia uma rede de ambulantes que 
sobreviviam ou complementavam renda com os lucros deste comércio e após a bilhetagem provavelmente tenham buscado outras atividades. Também destaca-se a dificuldade criada para as falsificações que fazem parte de uma rede criminosa que atua em todo o país e que ainda se beneficia desta atividade em outras cidades e regiões brasileiras. Aumento da segurança, ou pelo menos da sensação de segurança, é tema a ser melhor analisado devido a redução da atratividade a assaltos pela redução de valores (dinheiro e fichas) nas mãos do cobrador do ônibus. Embora não haja dados precisos sobre este último tema pode estar ocorrendo e se converter em um benefício extraordinário ao sistema de transporte público de passageiros.

\section{Considerações finais}

O presente trabalho optou por verificar a interveniência de representações do Estado como forma de alavancar o desenvolvimento de uma inovação. Pelos argumentos apresentados constatou-se que o sistema implementado proporcionou melhorias inovadoras às empresas de transporte coletivo nas regiões analisadas. Dados coletados e analisados pelos pesquisadores demonstraram a participação dos agentes governamentais neste processo que atuaram como indutores a criação e desenvolvimento da inovação agindo em acordo ao interesse público em favor dos usuários do serviço.

Embora as empresas tenham obtido benefícios diretos com a inovação e tenham sido beneficiadas do ponto de vista operacional e gerencial, porque não fizeram a implementação deste sistema antes? A bilhetagem já existe no Brasil desde o final do século passado, havendo sido implantada em cidades do nordeste e sudeste neste período. O entendimento dos pesquisadores é que não ocorreram antes devido à necessidade de investimentos de grande monta, pela falta de acordo e cooperação entre os operadores do serviço, já que com a bilhetagem o poder público aufere maior número de informações para controle sobre as empresas concessionárias do transporte público. Houve a necessidade da ação do Poder Concedente, via negociações induzir a implantação do sistema de bilhetagem encerrando um longo processo de discussão e de falta de ação por parte dos transportadores.

Coube ao Estado o papel de agente indutor do processo inovativo que proporcionou ganhos para todos os envolvidos no transporte (usuários, empresas e Poder Concedente). Tais argumentações evidenciam, nos casos estudados, uma correlação positiva entre a regulação e inovação, embora não possa ser feita uma generalização dos efeitos positivos da intervenção estatal nas atividades econômicas. Casos diferentes inclusive no mesmo setor precisam de análises detalhas para verificar a validade das observações feitas neste artigo em diferentes contextos e situações. O Estado pode agir de 
inúmeras formas tanto para catalisar o processo de inovação, retardá-lo ou mesmo não intervir e para cada situação específica cabe uma avaliação singular.

Fica reforçada a proposição das considerações deste trabalho, que não pretende ser generalista, mas focado em um contexto particular, em um dado momento que no futuro pode manter as características verificadas ou alterar-se ante a complexidade do macroambiente.

\begin{abstract}
This article was developed with the objective of determining if the regulators of public transportation activities can induce innovation processes. Therefore, we analyzed the creation, development and implementation of electronic ticketing system in three cities and a metropolitan region of Rio Grande do Sul. Field research included interviews with managers of transport companies, associations and representatives of transporters the Grantor and document analysis and historical survey of the sector specific legislation for electronic ticketing. The fieldwork resulted in qualitative data were analyzed with the application of content analysis. The conclusions point to the ticketing system has innovative features and the improvements offered by new combinations thereof, beyond the Grantor establish itself as a promoter of innovation providing gains for all involved in public transport (users, businesses and Grantor).
\end{abstract}

Keywords: innovation; regulation; electronic ticketing.

\title{
Referências
}

ALLEN, T. J. et al. Government of influence of process of innovation in Europe and Japan. Research Policy, v. 7, n. 2, p. 124-149, 1978.

AMATO NETO, J. Redes virtuais de pesquisa e inovação em serviços. In: BERNARDES, R,.; ANDREASSI, T. (Orgs). Inovação em serviços intensivos em conhecimento. São Paulo: Saraiva, p.303-321, 2007.

ARAGAO, J. J. G.; SANTOS, E. M. (Org.). Transporte em tempos de reforma - Ensaios sobre a problemática. 1. ed. Brasília: LGE, v. 1, 2000.

ARAGAO, J. J. G. et al. Sacudindo a poeira e construindo o novo ciclo de desenvolvimento do transporte público por ônibus. In: Enilson Santos; Joaquim Aragão. (Org.). Transporte em tempos de reforma. 1 ed. Brasília: LGE, v. 1, p. 33-52, 2000 .

de Transportes - GEIPOT, v. 1, 2001.

Transportes no Brasil: história e reflexões. 1. ed. Brasília: Empresa Brasileira de Planejamento

BARDIN, L.. Análise de conteúdo. Lisboa: Ed. 70, 1977.

BARRAS, R. Towards a theory of innovation in services. Research Policy, n. 15, p. 161-173, 1986.

BAUER, M. W.; GASKELL, G. Pesquisa qualitativa com texto, imagem e som. Petropólis: Vozes, 2002.

BERNARDES, R.; ANDREASSI, T. Apresentação. In: BERNARDES, R.; ANDREASSI, T. (Orgs). Inovação em serviços intensivos em conhecimento. São Paulo: Saraiva, 2007.

BESSANT, J. et al. Managing innovation beyond the steady state. Technovation, v. 25, n. 12, p. 1366-1376, 2005. 
BURLAMAQUI, L. Estado, Mercado, Regulação e Inovação: Law \& Economics em uma abordagem pós-Escola de Chicago. In: XIV Congresso Nacional do CONPEDI, 2005. Anais... Florianópolis: Fundao Boiteux, p. 377-379, 2005.

BYKFALVY, A. Innovation, entrepreneurship and outsourcing: essays on the use of knowledge in business environments. Girona: Programme Innovación empresarial - Department of business Administration and Product Design. University of Girona, 2007.

CAMACHO, F. Custos de capital de indústrias reguladas no Brasil. Revista do BNDES, v. 11, n. 21, p. 139-164, 2004.

CAMACHO, J. A.; RODRIGUEZ, M. How innovative are services? An empirical analysis for Spain. The Service Industries Journal. v. 25, n. 2, 2005.

cross ref

CHESBROUGH, H.; KARDON, A. Beyond high tech: early adopters of open innovation in other industries. R \& D Management, v. 36, n. 3, p. 229-236, 2006.

COASE, R.H. The nature of the firm. Econômica, n. 4, 1938.

COOPER, D. R.; SCHINDLER, P. S.. Métodos de pesquisa em administração. $7^{a}$ ed. Porto Alegre: Bookman, 2003.

CORIAT, B.; WEINSTEIN, O. Organizations, firms and institutions in the generation of innovation. Research Policy, v. 31, 273-290, 2002.

cross ${ }^{\text {ref }}$

DASCHS, B.; EBERRSBERGER, B.; LÖÖF, H. The innovative performance of foreign-owned enterprises in small open economies. Journal of Technology Transfer, v.33, n.4, p.393-407, 2008.

\section{cross ref}

DAVENPORT, T. H. Process Innovation: Reengineering Work through Information Technology. Harvard Business School Press, Cambridge, 1992.

DJELLAL, F.; GALLOUJ, F. Innovation and employment effects in services: a review of the literature and an agenda for research. The Service Industries Journal, v.27, n.3, p.193- 202, 2007.

\section{eross ref}

DURAND, T. Strategizing for innovation: competence analysis in assessing strategy change. In: HEENE, A; SANCHEZ, R. Competence-based strategic management. Chichester, England, p.127-150, 1997.

FLOYD, S. W.; LANE, P. J. Strategizing throughout the organization: managing role conflict in strategic renewal. Academy of Management Review, v.25, n.1, p.154-177, 2000.

cross ref

FRANCIS, D.; BESSANT, J. Targeting innovation and implications for capability development. Technovation, v.25, n.3, p. 171, 2005.

GALLAUGHER, J. Strategic oositioning and resource-based thinking: cutting through the haze of punditry to understand factors behind sustainable, successful internet businesses. International Journal of E-Business Research, v. 3, n. 3, p. 1425, 2007.

GALLOUJ, F.; SANSON, K. Economia da inovação: um balanço dos debates recentes. In: BERNARDES, R.; ANDREASSI, T. Inovação em serviços intensivos em conhecimento. São Paulo: Saraiva, p. 03-27, 2007. 
GIL, A. C. Como elaborar projetos de pesquisa. 4. ed. São Paulo: Atlas, 2002.

GODOY, A. S. A pesquisa qualitativa e sua utilização em Administração de Empresas. Revistas de Administração de Empresas, São Paulo, v. 35, n. 4, p. 20-29, 1995.

\section{cross ref}

GOMIDE, A. A.; ORINOCO FILHO, R. D. Concessões de serviços de ônibus urbanos: a necessária introdução da competitividade e o papel das licitações . In: SANTOS, E. M. dos; ARAGÃO, J. J. G. de. (Org.). Transporte em tempos de reforma - Ensaios sobre a problemática. 1 ed. Brasília: Linha Gráfica Editora, v. 1, p. 139-162, 2000.

HAIR, et al. Fundamentos de métodos de pesquisa em administração. Porto Alegre: Bookman, 2005.

HAMDANI, D. Serviços, criação de conhecimento e inovação. In: BERNARDES, R; ANDREASSI, T. Inovação em serviços intensivos em conhecimento. São Paulo: Saraiva, p. 29-56, 2007.

HIPP, C. Service peculiarities and the specific role of technology in service innovation management. International Journal of Services Technology and Management, v. 9, n. 2, 2008.

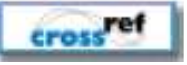

IBGE- Instituto Brasileiro de Geografia e Estatística. Contagem da População, 2011.

JACOBY, R.; RODRIGUEZ, D. Innovation, Growth, and Getting to Where You Want to Go. Design Management Review, v. 18, n. 1; 2007.

JONG, J. P. J.; VERMEULEN, P. A. M. Organizing successful new service development: A literature review.

Management Decision. v. 41, n. 9; p. 844-865, 2003.

cross ${ }^{\text {ref }}$

KEUPP, M. M.; GASSMANN, O. Determinantes and archetype users of open innovation. R\&D Management, v. 39, n. 4, p. 331-341. 2009.

cross ref

LOUNSBURY, M.; CRUMLEY, E. T. New practice creation: an institutional perspective on innovation. In: Organizational Studies. Sage publications, 2007.

MAVEL, M. R.; LUMPKIN, G. T. Technology entrepreneurs' human capital and its effects on innovation radicalness. Entrepreneurship Theory and Practice, v. 31, n. 6, 2007.

MORAES, R.. Análise de conteúdo. Revista Educação, n. 37, p. 7-32, 1999.

NELSON, R. R.; WINTER, S. G. Uma teoria evolucionária da mudança econômica. Campinas: Editora da Universidade Estadual de Campinas. 2005.

PASSOS. C. A. Novos modelos de gestão e as informações. In: LASTRES. H. M. M.; ALBAGLI. S. Informação e globalização na era do conhecimento. Rio de Janeiro: Campus, 1999.

POSSAS, M.; FAGUNDES, J.; PONDÉ, J. Custos de transação e políticas de defesa da concorrência. Revista de Economia Contemporânea, n.2, 1998.

RICHARDSON, R. J. (Cood.). Pesquisa social: métodos e técnicas. 4ª.ed. São Paulo: Atlas, 1999.

SANTOS, E. Concentração em mercados de ônibus urbanos no Brasil: uma análise do papel da regulamentação. Tese de doutorado, Programa de Pós-graduação em Engenharia de Transportes/COPPE/UFRJ, Rio de Janeiro, 2000.

SCHUMPETER, J. A. A teoria do desenvolvimento econômico. São Paulo: Abril Cultural, 1982. 
SCHUMPETER, J. A. Capitalismo, socialismo e democracia. Rio de Janeiro: Fundo de Cultura, 1942.

SHETH, J.N.; RAM, S. Bringing innovation to market: How to Break Corporate and Customer Barriers. Wiley \& Sons, New York: 1987.

SIMMIE, J.; STRAMBACH, S. The contribution of KIBS to innovation in cities: an evolutionary and institutional perspective. Journal of Knowledge Management, v. 10, n. 5; p. 26-37, 2007.

cross ref

SIMÕES, S. P. Significado e possibilidades da análise de conteúdo. Tecnologia educacional, v. 20, n. 102/103, p. 54-57, 1991.

SMITH, R. The evolution of innovation. Research Technology Management. v. 51, n. 3, p. 51-55, 2008.

SOUZA JÚNIOR, R. T. Sistema de transporte público de passageiros do RS: Uma Análise Sob a Ótica Regulatória. Marco Regulatório. Revista AGERGS, v. 9, p. 47-70, 2006.

SUNDBO, J.; GALLOUJ, F. Innovation in services, Oslo, Noruega. Disponivel em :

<http://www.step.no/old/Projectarea/si4s/index.htm>, 1998. Acesso em: 15 de nov de 2009.

TARAFDAR, M; GORDON, S. R. Systems competencies on process innovation: A resource-based view. The Journal of Strategic Information Systems, v. 16, n. 4, p. 353-392, 2007.

cross ref

TETHER, B. Do Services innovate (differently)? Insights from the european innobarometer Survey. Industry and Innovation. v. 12, n. 2, 2005.

cross ref

WILLIAMSON, O. E. Transaction-cost economics: the governance of contractual relations. Journal of Law and Economics, v. 22, n. 2, p. 223-261, 1979.

cross ref

YIN, R. K. Estudo de caso: planejamento e métodos. $2^{\mathrm{a}}$ ed. Porto Alegre: Bookman, 2001.

\section{Dados dos autores:}

Nome completo: Rafael Mendes Lübeck

Filiação institucional: PPGA/UFSM - Universidade Federal de Santa Maria

Departamento: $\mathrm{CCSH}$

Função ou cargo ocupado: Pesquisador colaborador

Endereço: Avenida Roraima, nº 1000 (Rua Q), CCSH, Prédio 74-C, Bairro Camobi , Santa Maria - RS, CEP: 97105-900

Telefones para contato: (55) 3220.9258 - (55) 3220.9312

e-mail: rafael.lubeck@gmail.com

Nome completo: Milton Luiz Wittmann 
Filiação institucional: PPGA/UFSM - Universidade Federal de Santa Maria

Departamento: $\mathrm{CCSH}$

Função ou cargo ocupado: Professor associado

Endereço: Avenida Roraima, no 1000 (Rua Q), CCSH, Prédio 74-C, Bairro Camobi, Santa Maria - RS, CEP: 97105-900

Telefones para contato: (55) 3220.9258 - (55) 3220.9312

e-mail: wittmann@profwittmann.com

\section{Nome completo: Angélica Skrebsky Richter}

Filiação institucional: Curso de Mestrado em Administração UFSM - Universidade Federal de Santa Maria

Departamento: CCSH

Função ou cargo ocupado: Bolsista CAPES

Endereço: Avenida Roraima, no 1000 (Rua Q), CCSH, Prédio 74-C, Bairro Camobi, Santa Maria - RS, CEP: 97105-900

Telefones para contato: (55) 3220.9258 - (55) 3220.9549

e-mail: angelica.keca@gmail.com

Nome completo: Marcia Santos da Silva

Filiação institucional: PPGA/UFSM - Universidade Federal de Santa Maria

Departamento: $\mathrm{CCSH}$

Função ou cargo ocupado: Pesquisadora colaboradora

Endereço: Avenida Roraima, no 1000 (Rua Q), CCSH, Prédio 74-C, Bairro Camobi, Santa Maria - RS, CEP: 97105-900

Telefones para contato: (55) 3220.9258 - (55) 3220.9312

e-mail: mssrs@ @terra.com.br

Recebido em: 28/06/2011

Aceito em: 24/09/2012 